\title{
The Design of Real-time Monitoring System for Operation State of High Voltage Circuit Breaker
}

\author{
Zhenhao WANG ${ }^{1, \text { a }}$, Ming LIU ${ }^{2, \mathrm{~b}}$, Dan PANG ${ }^{3, \mathrm{c}}$ \\ ${ }^{1}$ Northeast Dianli University, Jilin Jilin 132012, China \\ ${ }^{2}$ Baishan Power Supply Company, Jilin Baishan 134300, China \\ ${ }^{3}$ State Grid Jilin Electric Power Company Limited Changchun Power Supply Company, Changchun, \\ Jilin Changchun 130021, China \\ aemail: zhenhaowang@126.com, bemail: 2791869323@qq.com, 'email: 13844109937@163.com
}

Keywords. The Circuit Breaker; The Opening or Closing Coils; Vibration

\begin{abstract}
This paper discusses the principle design of real-time monitoring system for high voltage circuit breaker operation, monitoring and analysis for the monitoring principle and mechanical characteristics of the opening or closing coils.The devices are used in substation, and the actual monitoring data can response the operation state of circuit breaker.
\end{abstract}

\section{Introduction}

High voltage circuit breaker is one of the most important equipment in power system, which has an irreplaceable role in ensuring the normal operation of the power system and removal system failure, therefore, the normal operation of high voltage circuit breaker is crucial.

The system is mainly conducted on the real-time monitoring for circuit breaker opening or closing coils current, switching time, and the mechanical characteristics of its operation mechanism and so on, and do the real-time data acquisition for the parameters that may affect normal operation, analysis, processing and calculation [1]. You could judge whether the circuit breaker operating in the qualified range through the system, and it can be found that the change trend. The system can be used to guide the production maintenance, arrange maintenance, improve the management level of the circuit breaker.

\section{The overall structure design of the monitoring system}

Real-time monitoring and diagnosis system for operation condition of high voltage circuit breaker use the hierarchical distributed field bus structure, which is composed of switch monitoring subsystem installed in substation and data management, analysis system installed in the users, and can do the real-time monitoring, comprehensive analysis on mechanical vibration, coil current characteristic, breaking current parameters of opening or closing simultaneity of high voltage switching device. The user through a local area network (LAN) to take a number of substation monitoring and data collection to the data management center and diagnostic center, and do the comprehensive judgment of running state of high voltage circuit breaker [2][3]. The figure of hardware structure is as follows: 


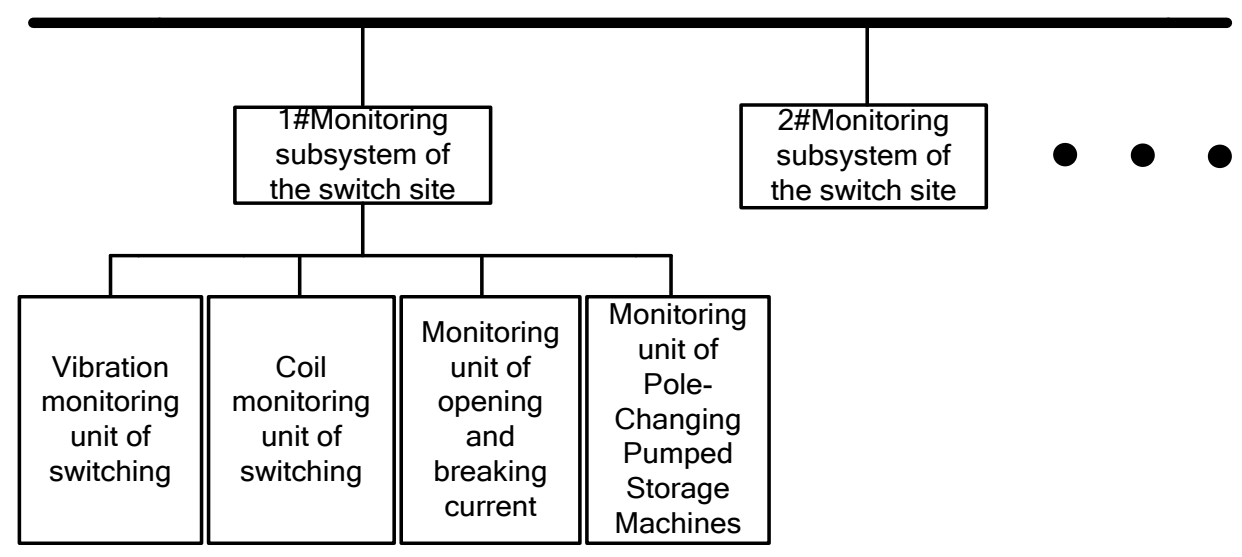

Fig.1. The overall structure of system

Each function unit collects the real-time data by the bus to the corresponding switch monitoring subsystem, Each switch monitoring system is connected to the host of monitoring system station through the CAN2.0B field bus, forming networking or independent monitoring data analysis system to manage, analyze data and diagnose the fault.

\section{Monitoring of the opening or closing coils current}

The current of opening or closing coils is also an important content for monitoring the circuit breaker status. It can be easily get the current of opening or closing coils by hall sensor.

By monitoring current waveform of opening or closing coils can obtain the information of circuit breaker status, the key lies in extracting the features of opening or closing coils current waveform contour. It can be found that time characteristic parameters in the waveform corresponds to the motion event of core through analysis of the former waveform, so by extracting the time characteristic parameters in current waveform can obtain state characteristics of circuit breaker.

This article adopts the method of determine the total number of peaks and troughs to determine whether it is normal waveform. If there are two peaks and a trough after a judgment, the open circuit is normal open circuit; Otherwise, it is not normal open circuit. Judging the peaks and troughs of ordinal number when it is normal open circuit, then according to the sampling interval to calculate the corresponding time of peaks and troughs; Calculating the biggest difference between the amplitude of peaks and troughs in sampling sequence, and screening out when it is abnormal open circuit. Fig.2 is the recorded current waveform of the closing coil of in this system, compared with the typical waveform and according to similarity can determine that the circuit breaker is in the healthy operation state [4].

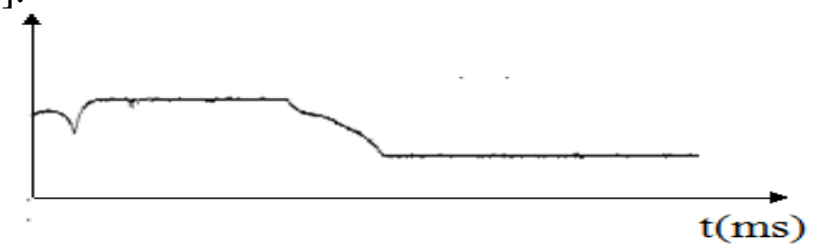

Fig.2. The actual current waveform of closing coil

\section{The vibration monitoring of switching}

Faults of circuit breaker are usually mechanical failure, vibration waveform produced by mechanical operation and current waveform of opening or closing coils, which contains abundant information of circuit breaker. In the actual process of analysis, finding out the characteristic quantity by the analysis of collected vibration information, try to represent the process by the least 
characteristic parameters, so as to distinguish difference between normal and abnormal state. But a lot of time domain analysis of the characteristics of the vibration signal showed that the dispersion is bigger, poor repeatability and also found some vibration waves whose time domain are different obviously are normal waves, and the identical vibration could have bigger differences in local by sampling again and disposing [5]. Therefore, only by using time domain index as characteristics of vibration signals of circuit breaker operation is not scientific. This article uses the discrete envelope statistics to extract envelope information from the vibration signals.

Supposing time-domain discrete vibration signal of $\mathrm{N}$ points is $\mathrm{s}(\mathrm{i}), 0 \leq \mathrm{i} \leq \mathrm{N}-1$, so the $\mathrm{DES}$ is defined as:

$$
S(i)=\sqrt{s^{2}(i)-s(i-1) \times(i+1)} \quad 0 \leq i \leq N-1
$$

Subtracting the product of adjacent two points from the square of each sampling value can reduce harmonic components introduced by the squared term. The measured vibration waveform shown in Fig. 3 could characterize the envelope of vibration signal.

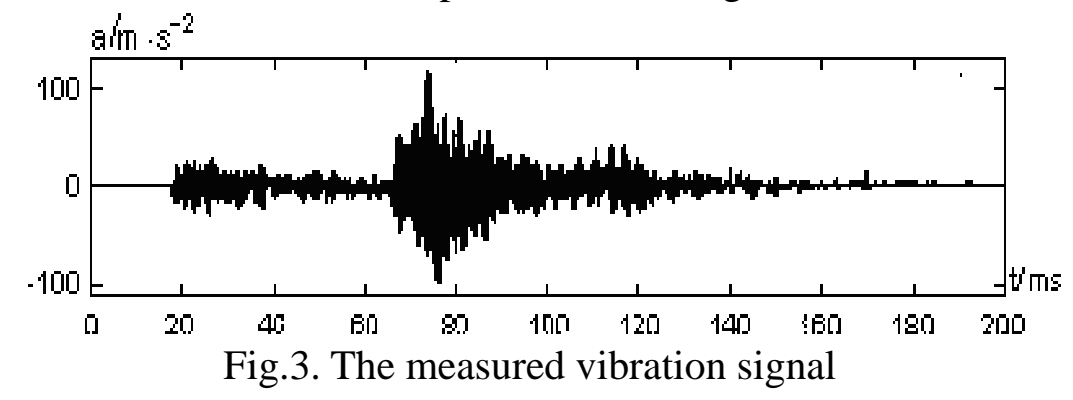

\section{Field test}

All the monitoring waveform can be displayed on the same time-axis of the main interface of PC by this system. and can display the time of various points which is convenient for operators to compare. Taking the recorded waveform for switching operation of a bypass SW-220 circuit breaker in the actual substation as an example, then the waveform is shown in Fig.4.

The starting time of circuit breaker operation is based on whether there is current in break-brake electromagnet coil, the actual action to be achieved is indicated by the status of auxiliary contactor (normally open). By the definition of break-brake time (the interval between the moment of achieving break-brake instruction and all pole contactors separation moments). In Fig.4, switch jump time corresponds to the tripping time when tripping coil current is biggest, breaking current extinguishes arc in natural zero crossing and this moment is called the on-off time, the difference between the two is the arcing time, from the start time to the moment of maximum time of the vibration signal of vibration event corresponds to contact travel time, and the connecting speed of circuit breaker can be calculated through it. The breaking time and contact travel will not change a lot when the circuit breaker operates normally, the dispersion is 1ms around. The system will give warning that the breaker is abnormal when the above time parameters change greatly.

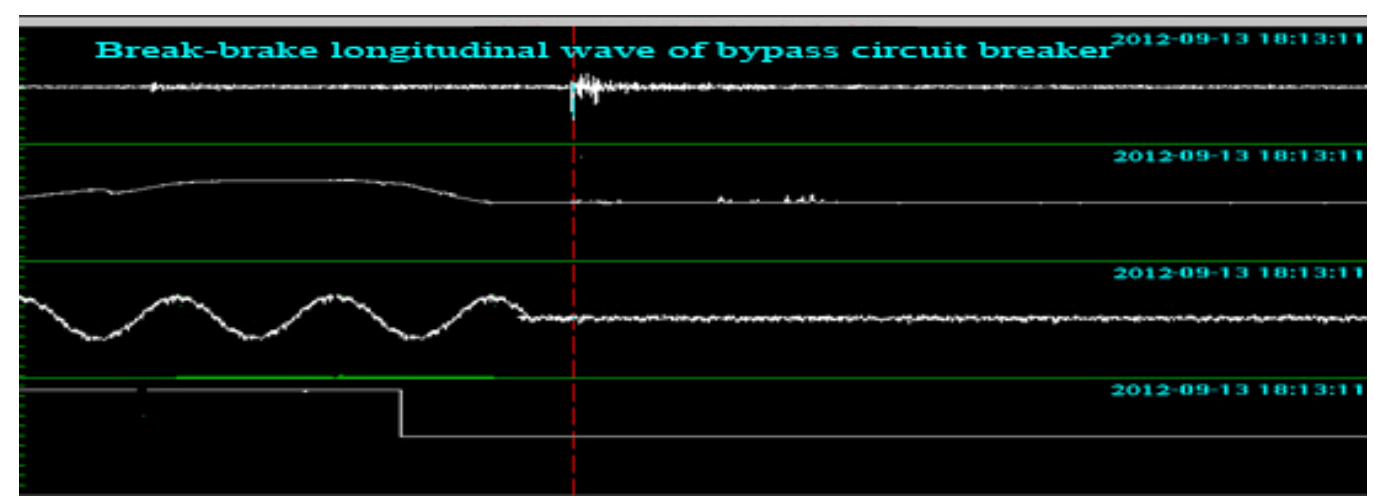

Fig.4. The measured waveform 


\section{References}

[1] C.Sweetser, W.J.(Bill)Bergman, A.Mannarino, et al. Strategies for Selecting Monitoring of Circuit Breakers. IEEE Transactions on Power Delivery, 200217 (3) 742-746.

[2] Michael Stanek, Klaus Frohlich. Model-aided Diagnosis-A New Method for Online Condition Assessment of High Voltage Circuit Breakers. IEEE Transactions on Power Delivery, 200015 (2) 585-590.

[3] R.G.Bruce, A Wright. Remanent Flux in Current-transformer Core. Proceedings of The Institution of Electrical Engineers, 1966113 (5) 915-920.

[4] S.Y.Park, M.L.Lai, C.C.Lin, et al. Measurements for Noninvasive Mechanical Diagnostics of Power Circuit Breakers. Electric Power Systems Research, 199019 1-10.

[5] A.A.Polycarpou, A.Soom, V.Swarnakar. Event Timing and Shape Analysis of Vibration Bursts from Power Circuit Breakers. IEEE Transactions on Power Delivery, 199611 (2) 848-857. 